\title{
A COMPARATIVE EVALUATION OF FLUID PRELOADING VS. CO-LOADING ON MATERNAL HAEMODYNAMICS AND NEONATAL OUTCOME FOR THE PARTURIENTS UNDERGOING EMERGENCY CAESAREAN DELIVERY- A PROSPECTIVE, RANDOMISED, DOUBLE-BLIND, PARALLEL GROUP STUDY
}

\author{
Partha Sarathi Halder1, Anjan Das², Debabrata Mandal3, Hirak Biswas, Sandip Roy Basunia5, Tapobrata Mitra6, \\ Surajit Chattopadhyay ${ }^{7}$, Subrata Kumar Mandal ${ }^{8}$
}

\begin{abstract}
${ }^{1}$ Associate Professor, Department of Anaesthesiology, College of Medicine and Sagore Dutta Hospital, Kolkata, West Bengal, India. ${ }^{2}$ Associate Professor, Department of Anaesthesiology, College of Medicine and Sagore Dutta Hospital, Kolkata, West Bengal, India. ${ }_{3}^{3}$ Assistant Professor, Department of Oral and Maxillofacial Surgery, Malda Medical College, Malda, West Bengal, India. ${ }_{4}^{4}$ Assistant Professor, Department of Anaesthesiology, College of Medicine and Sagore Dutta Hospital, Kolkata, West Bengal, India. ${ }^{5}$ Assistant Professor, Department of Anaesthesiology, Midnapore Medical College, West Midnapore, West Bengal, India. ${ }^{6}$ Assistant Professor, Department of Anaesthesiology, Murshidabad Medical College, Berhampore, West Bengal, India. ${ }^{7}$ Assistant Professor, Department of Anaesthesiology, College of Medicine and Sagore Dutta Hospital, Kolkata, West Bengal, India. ${ }^{8}$ Professor and HOD, Department of Anaesthesiology, College of Medicine and Sagore Dutta Hospital, Kolkata, West Bengal, India.
\end{abstract}

\section{ABSTRACT}

\section{BACKGROUND}

Emergency caesarean section (CS) is very often done under spinal anaesthesia unless contraindicated. This neuraxial block results in hypotension caused by pharmacological sympathectomy. This effect can lead to cardiovascular side effects like hypotension, bradycardia, nausea, at the same time foetal jeopardy like foetal hypoxia and acidosis. These side effects can be prevented either by preloading with a crystalloid or simultaneous co-loading during intraoperative period. Here, in this prospective, double-blind study, we had compared the incidence of hypotension in intraoperative period and the foetal outcome in two groups.

\section{MATERIALS AND METHODS}

This prospective, randomised, double-blind, parallel group study was conducted in obstetric emergency OT of a tertiary care centre. 100 primigravida mothers aged between 18 - 29 years with ASA I physical status, posted for emergency CS due to foetal distress was randomly allocated for either preloading (Group P) or co-loading (Group C).

\section{RESULTS}

Fluid requirement was significantly less in co-loading group. There was no significant difference in the incidence of hypotension and ephedrine use. Foetal outcome in 1 min Apgar in Group C was significantly better, as the baby could be delivered quickly in Group C.

\section{CONCLUSION}

It is evident from our study that preloading can safely be avoided for spinal anaesthesia in CS posted for foetal distress. By using co-loading method, we can save valuable time required to deliver the baby and avoid circulatory overload without increasing incidence of hypotension.

\section{KEY WORDS}

Preloading, Co-loading, Hypotension, Foetal Distress, Heart Rate (HR), SIH (Spinal Induced Hypotension), CVSE (Cardiovascular Side Effects), Systolic Blood Pressure (SBP), RL (Ringer's Lactate), FHR (Foetal Heart Rate).

HOW TO CITE THIS ARTICLE: Halder PS, Das A, Mandal D, et al. A comparative evaluation of fluid preloading vs. co-loading on maternal haemodynamics and neonatal outcome for the parturients undergoing emergency caesarean delivery- a prospective, randomised, double-blind, parallel group study. J. Evolution Med. Dent. Sci. 2018;7(25):2949-2953, DOI: $10.14260 /$ jemds/2018/664

\section{BACKGROUND}

Preloading with crystalloid before administering spinal anaesthesia has been widely practiced to prevent intraoperative hypotension by anaesthesiologists.[1] This practice often hinders immediate administration of spinal anaesthesia even in emergency caesarean section posted for

'Financial or Other Competing Interest': None.

Submission 09-05-2018, Peer Review 01-06-2018,

Acceptance 08-06-2018, Published 18-06-2018.

Corresponding Author:

Dr. Anjan Das,

\#174, Gorakshabashi Road,

Royal Plaza Apartment, $4^{\text {th }}$ Floor, Flat No. 1,

Nagerbazar, Kolkata-28, West Bengal, India.

E-mail:anjan2k8@yahoo.com

DOI: $10.14260 /$ jemds $/ 2018 / 664$ (c) (i) $\odot$ non-reassuring foetal status, commonly termed as foetal distress.

The wastage of time for preloading may further jeopardise the foetus or it may compel the anaesthesiologist to go for general anaesthesia, which is known to have increased incidence of morbidity and mortality for both mother and foetus.[2-4] On the other hand, hypotension associated with spinal anaesthesia may impair uteroplacental circulation which may also jeopardise foetal oxygenation. ${ }^{[5]}$ For last two decades the concept of co-loading (Infusion of fluid at the time of administering spinal anaesthesia) has come to vogue and several studies, both in pregnant and nonpregnant patients were done.[6,7] In our study, we have compared preloading with co-loading in emergency caesarean section for foetal distress. Aim of our study was to compare the incidence of hypotension intraoperatively and foetal outcome in two groups. 


\section{MATERIALS AND METHODS}

This is a prospective, randomised, double-blind, parallel group study. After Institutional Ethics Committee approval and informed patient consent, 100 primigravida mothers of age group 18 - 29 yrs. belonging to ASA physical status I posted for emergency caesarean section for foetal distress were allocated into one of the two groups (Group P or Group C) through a computer generated random number before transferring to operation theatre.

\section{Sample Size Estimation}

Amount of fluid administration for maintaining stable haemodynamics among two groups was used for sample size calculation. The average amount in each group was $1600 \mathrm{~mL}$ and to detect a difference of $10 \%$ (i.e. $160 \mathrm{~mL}$ ), at the $\mathrm{p}<0.05$ level with a probability of detecting a difference, if it exists of 80 percent $(1$-beta $=0.80)$. On the basis of previous study assuming within Group SD of $60 \mathrm{~mL}$ and we needed to study at least 47 parturients per group to be able to reject the null hypothesis, which will be increased to 50 patients for possible dropouts.

\section{Inclusion Criteria Includes}

1. Term pregnant patients (Gestational period 37 - 42 weeks) with vertex presentation,

2. Clinical evidence of foetal distress,

1. FHR $>160 / \mathrm{min}$ or $<120 / \mathrm{min}$,

2. FHR takes long time to come back after contraction phase passes off,

3. Irregular heart rate,

4. Meconium stained liquor.[8]

\section{Exclusion Criteria Includes}

1. Congenital foetal anomaly.

2. IUGR baby.

3. Medical or surgical disease of mother.

4. Relative and absolute contraindication of spinal anaesthesia.

Baseline measurement of heart rate (HR), blood pressure (NIBP) and $\mathrm{O}_{2}$ saturation $\left(\mathrm{SpO}_{2}\right)$ was measured after transferring the patient to operation theatre in a modified supine position with at least 15 left lateral tilt.

One 18G cannula was inserted to all the patients and infusion Ringer's Lactate was started. Patients belonging to Group P received RL at a rate of $15 \mathrm{~mL} / \mathrm{kg}$ over 20 mins prior to administering spinal anaesthesia (Preloading). Patients in Group C received same infusion at a rate of 20 drops/min prior to spinal anaesthesia to maintain the cannula. Group $\mathrm{C}$ received $15 \mathrm{~mL} / \mathrm{kg} \mathrm{RL}$ over 20 mins after administration of spinal anaesthesia (Co-loading) and $20 \mathrm{~mL} / \mathrm{min}$ after 20 mins. Group P received RL @ $20 \mathrm{~mL} / \mathrm{min}$ after spinal anaesthesia was administered. Infusion RL was continued @ $20 \mathrm{~mL} / \mathrm{min}$ upto $1 \mathrm{hr}$ after starting the operation in both groups, then reduced to $10 \mathrm{~mL} / \mathrm{min}$ if operation continued beyond $1 \mathrm{hr}$. Administration of preoperative and intraoperative fluid was managed and monitored by a dedicated anaesthesiologist. A second anaesthesiologist who was unaware of the patient's preloading status administered spinal anaesthesia and recorded intraoperative vitals and the incidence of hypotension, bradycardia, hypoxia, foetal outcome etc.

Hyperbaric $0.5 \%$ bupivacaine was injected intrathecally between L3-4 or L4-5 interspace with the patient in sitting position at the dose of $0.25 \mathrm{mg} / \mathrm{kg}$ body weight upto a maximum total dose of $15 \mathrm{mg}$ with $25-\mathrm{G}$ Quincke needle. The patient was then turned rapidly to left modified supine position. The extension of spinal blockade was assessed by cold temperature discrimination using wet cotton ball.[9] $\mathrm{O}_{2}$ at a rate of $2 \mathrm{~L} / \mathrm{min}$ was given to all patients via nasal prong till the delivery of the baby. Continuous monitoring of HR and $\mathrm{SpO}_{2}$ were done. SBP and DBP at 2, 4, 6, 8, 10, 15, 20, 25 and 30 mins were recorded and used for data analysis.

All blocks extended to above $\mathrm{T}_{6}$ level before surgery was allowed to start. Spinal Induced Hypotension (SIH), Cardiovascular Side Effects (CVSE) and condition of the baby were the main study outcomes. SIH was defined as a decrease of $>30 \%$ in baseline systolic blood pressure or SBP $<90$ mmHg.[7,10,11] CVSE were defined as SIH plus clinical symptoms (Nausea, vomiting or faintness) requiring treatment.[10] At the beginning of the procedure, patients were instructed to report any episode of nausea or faintness occurring during the intervention. Patients were unaware of what treatment they were receiving. All patients developing SIH and CVSE were treated with $200 \mathrm{~mL}$ of RL bolus followed by $6 \mathrm{mg}$ of bolus ephedrine after 3 mins if SBP does not increase. Further dose of ephedrine ( $3 \mathrm{mg}$ ) were repeated after 5 mins if deemed necessary.[12] Bradycardia was defined as heart rate $<60 / \mathrm{min}$ and treated with $0.6 \mathrm{mg}$ of atropine. Additional dose of $0.3 \mathrm{mg}$ was repeated after 2 mins if necessary. Maximum height of block was identified during the procedure. Time between spinal injection and surgery, uterine incision and delivery, incidence of SIH and CVSE were noted. Total dose of vasopressor received and the Apgar score of the baby at $1 \mathrm{~min}$ and $5 \mathrm{mins}$ were recorded. All patients received $10 \mathrm{U}$ of oxytocin after delivery of the baby.

\section{Statistical Analysis}

Raw data were entered into MS Excel spreadsheet and analysed using standard statistical software SPSS $\mathbb{R}$ statistical package version 18.0 (SPSS Inc., Chicago, IL, USA). Derived values were expressed as number (\%) or mean \pm S.D and/or standard error (S.E). Pearson's chi-square test was used to analyse categorical variables. Independent sample ' $t$ ' test was used to analyse normally distributed continuous variables. One-way ANOVA test was used to determine difference between the means of different independent groups. Nonparametric alternative Mann Whitney-U test was used to compare other variables in the study and control groups in different points of time. $\mathrm{P}$ value $<0.05$ was considered statistically significant.[13]

\section{RESULTS}

The groups were comparable in age, weight, height, duration of surgery and level of block [Table-1]. There is also no significant difference in uterine incision- delivery interval and block delivery interval among two groups [Table-1]. Intraoperative fluid requirement is significantly $(p<0.05)$ higher in Group $C$, whereas preloading volume was significantly $(\mathrm{p}<0.05)$ higher in Group P [Table-2]. Total dose of vasopressor used as ephedrine is quite comparable among two groups. On the other hand, total amount of fluid administered in Group P is significantly $(p<0.05)$ higher than Group C [Table-2]. There is no significant ( $p>0.05)$ difference in the number of patients who became hypotensive, episodes of hypotension, bradycardia and ephedrine requirement [Table-3]. Foetal outcome at $1 \mathrm{~min}$ 
Apgar is significantly better in Group $\mathrm{C}$ and significantly less no. of babies of Group C had 1 min Apgar < 8, but no significant difference in both groups at 5 mins Apgar [Table3]. 4 patients of Group $P$ and 5 patients of Group $C$ received Inj. Ondansetron $4 \mathrm{mg}$ IV for nausea and vomiting. Other patients developing CVSE responded with correction of blood pressure. Intraoperative systolic blood pressures are compared among two groups and found to be significant at 15, 20, 25 mins after spinal anaesthesia [Figure-1]. Intraoperative diastolic blood pressures and heart rates are compared among two groups and found to be statistically significant [Figure-2 and 3 respectively].

\begin{tabular}{|c|c|c|c|}
\hline $\begin{array}{c}\text { Demographic } \\
\text { Parameters }\end{array}$ & $\begin{array}{c}\text { Group P } \\
(\mathbf{n = 5 0 )}\end{array}$ & $\begin{array}{c}\text { Group C } \\
(\mathbf{n = 5 0 )}\end{array}$ & P value \\
\hline Age (yrs.) & $23.45 \pm 3.1$ & $22.32 \pm 3.2$ & 0.4294 \\
\hline Weight (kg) & $55.7 \pm 5.5$ & $55.6 \pm 6.3$ & 0.1190 \\
\hline Haemoglobin (gm\%) & $12.23 \pm 2.32$ & $13.44 \pm 2.84$ & 0.0987 \\
\hline Height (cm) & $63.6 \pm 7.1$ & $66.5 \pm 8.1$ & 0.1878 \\
\hline $\begin{array}{c}\text { Block delivery } \\
\text { interval (mins) }\end{array}$ & $12.6 \pm 3.5$ & $13.1 \pm 4.2$ & 0.5193 \\
\hline $\begin{array}{c}\text { Uterine Incision } \\
\text { Delivery (sec) }\end{array}$ & $38.5 \pm 9.5$ & $36.8 \pm 8.9$ & 0.3581 \\
\hline $\begin{array}{c}\text { Duration of Surgery } \\
\text { (mins) }\end{array}$ & $62.71 \pm 10.33$ & $57.88 \pm 9.62$ & 0.0872 \\
\hline $\begin{array}{c}\text { Level of Block } \\
\text { (median) }\end{array}$ & $\mathrm{T}_{\mathbf{5}}$ & $\mathrm{T}_{\mathbf{4}}$ & 0.2134 \\
\hline
\end{tabular}

Table 1. Demographic Profile of Mothers and the Operative Details

\begin{tabular}{|c|c|c|c|}
\hline $\begin{array}{c}\text { Demographic } \\
\text { Parameters }\end{array}$ & $\begin{array}{c}\text { Group P } \\
(\mathbf{n}=50)\end{array}$ & $\begin{array}{c}\text { Group C } \\
(\mathbf{n}=50)\end{array}$ & P value \\
\hline $\begin{array}{c}\text { Preload } \\
\text { volume (mL) }\end{array}$ & $805.45 \pm 79.7$ & $10.3 \pm 7.5$ & 0.0001 \\
\hline $\begin{array}{c}\text { Intraoperative } \\
\text { fluid (mL) }\end{array}$ & $1053.56 \pm 57.8$ & $1456.59 \pm 78.9$ & 0.0001 \\
\hline $\begin{array}{c}\text { Dose of } \\
\text { ephedrine (mg) }\end{array}$ & $7.6 \pm 2.5$ & $8.1 \pm 2.7$ & 0.3390 \\
\hline $\begin{array}{c}\text { Total fluid } \\
\text { requirement till } \\
\text { end of operation }\end{array}$ & $1859.01 \pm 60.67$ & $1466.89 \pm 68.71$ & 0.0001 \\
\hline $\begin{array}{c}\text { Table 2. Vasopressor (Ephedrine) and Fluid Requirement } \\
\text { among Two Study Groups }\end{array}$ \\
\hline
\end{tabular}

\begin{tabular}{|c|c|c|c|}
\hline & $\begin{array}{c}\text { Group P } \\
(\mathbf{n = 5 0 )}\end{array}$ & $\begin{array}{c}\text { Group C } \\
(\mathbf{n = 5 0 )}\end{array}$ & P value \\
\hline $\begin{array}{c}\text { No. of patients who became } \\
\text { hypotensive }\end{array}$ & 18 & 17 & 0.7652 \\
\hline $\begin{array}{c}\text { Total episodes of } \\
\text { hypotension }\end{array}$ & 23 & 21 & 0.5688 \\
\hline $\begin{array}{c}\text { Cardiovascular side effects } \\
\text { (CVSE) }\end{array}$ & 13 & 11 & 0.4947 \\
\hline $\begin{array}{c}\text { Episodes of hypotension } \\
\text { requiring ephedrine bolus }\end{array}$ & 21 & 20 & 0.7728 \\
\hline $\begin{array}{c}\text { Episodes of hypotension } \\
\text { requiring 2 } \\
\text { ephedrine }\end{array}$ & 7 & 8 & 0.6835 \\
\hline $\begin{array}{c}\text { No. of patients having } \\
\text { bradycardia }\end{array}$ & 9 & 8 & 0.6835 \\
\hline Apgar score at 1 min & $7.6 \pm 0.76$ & $8.8 \pm 0.28$ & 0.0001 \\
\hline Apgar score < 8 at 1 min & 12 & 5 & 0.0009 \\
\hline Apgar score at 5 mins & $9.21 \pm 0.19$ & $9.32 \pm 0.18$ & 0.0037 \\
\hline Apgar score < 8 at 1 min & 3 & 2 & 0.4704 \\
\hline Table 3. Intraoperative Hypotension, Bradycardia and \\
Neonatal Characteristics & \\
\hline
\end{tabular}

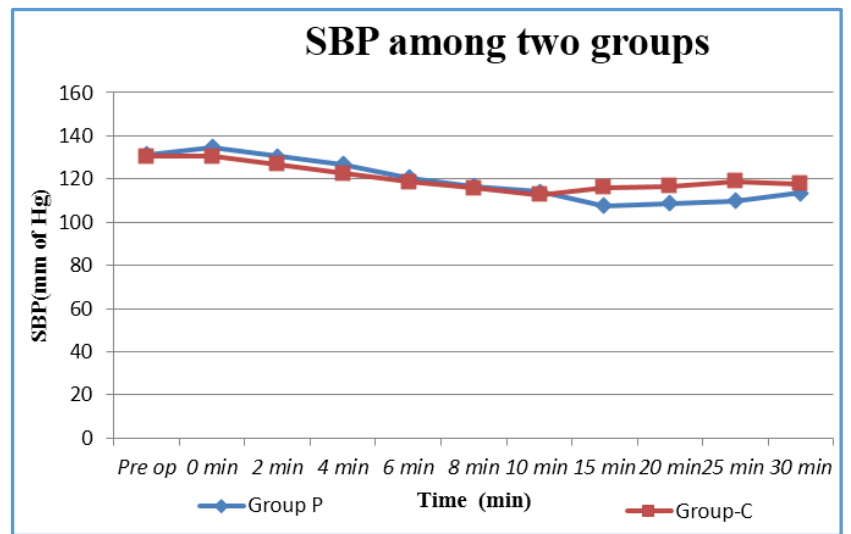

Figure 1. Comparison of Systolic Blood Pressure (SBP) among Two Groups

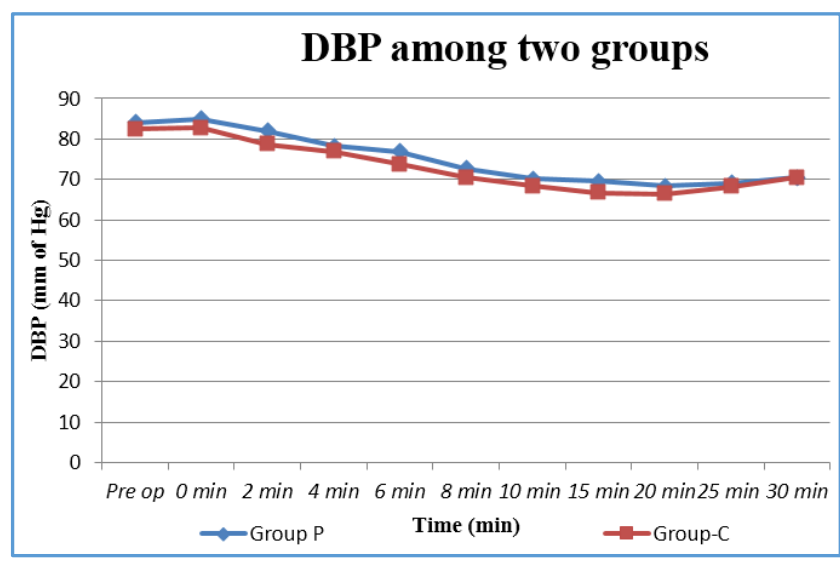

Figure 2. Comparison of Diastolic Blood Pressure (DBP) among Two Groups

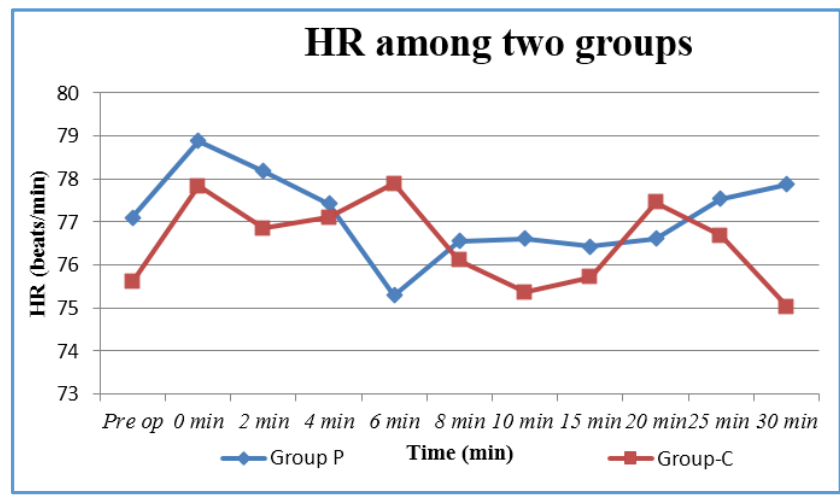

Figure 3. Comparison of Heart Rate (HR) among Two Groups

\section{DISCUSSION}

More than $30 \%$ of the patients receiving spinal anaesthesia develop SIH.[14] There are several measures to prevent or reduce the incidence of hypotension like left uterine displacement, use of vasopressor, leg elevation and preloading. [12] Preloading with crystalloid is one of the most common techniques among the anaesthesiologists to reduce the incidence of hypotension. Previous studies have used 15$20 \mathrm{~mL} / \mathrm{kg}$ of RL for preloading in caesarean section. ${ }^{77,15,16] ~ I n ~}$ our study, we have preloaded our patients of Group P with 15 $\mathrm{mL} / \mathrm{kg}$ of RL.

In caesarean section of the patients with foetal distress where imminent delivery of the baby is warranted, preloading may waste valuable time. As spinal anaesthesia is 
not contraindicated and is less costly than GA, it is preferable to go for spinal anaesthesia even in case of foetal distress.[17] Most of the studies also have shown that Apgar score of the babies delivered under spinal anaesthesia is better than those delivered under general anaesthesia.[3,17] In rural India, where most of the patients coming to Govt. hospital are below poverty line. The cost of general anaesthesia is an additional financial burden on the patients.

In addition to being time consuming, preloading may cause circulatory overload in pregnant mothers, particularly after delivery which normally manifested by raised CVP.[16] The extra load is not so harmful in patients with normal cardiovascular function, but may be potentially dangerous in patients with myocardial insufficiency and preeclampsia leading to pulmonary oedema.[11] Pregnant patients are more susceptible to pulmonary oedema due to increased permeability of pulmonary capillaries.[18]

In our study, we have found no significant difference in the incidence of hypotension and CVSE among the two groups. Our observation is similar to the previous studies. $[6,7,11,16]$ In our study though there is no statistically significant difference, the incidence of hypotension is slightly more in patients who were preloaded compared to those who were co-loaded. The crystalloid fluid which was used for preloading 15 - 20 mins before spinal anaesthesia has relatively short intravascular half-life. Since $75 \%$ of any crystalloid diffuses into the interstitial space, its efficacy in expanding plasma volume is only transient.[19] On the other hand, when fluid was administered along with administration of spinal anaesthesia (i.e. in co-loading) expanded intravascular compartment is filled up as there is sympathetic blockade induced venodilatation, therefore less chance of circulatory overload.

In our study, we have found that in the patients who received preloading has a slight higher initial SBP than those who did not. But fall of SBP is more in patients who were preloaded after 10 mins. The patients who received bolus fluid after spinal anaesthesia (i.e. co-loaded) has significantly less fall in SBP than the other group. Our observation is similar to the observations made by Jose L et al.[7]

Some of the studies have shown that preloading and coloading with colloids may be more helpful to reduce the incidence of SIH and CVSE, but the cost of colloid and risk of anaphylactic reaction with colloid do not make it a suitable and widely acceptable alternative of crystalloid.[20,21]

Regarding the neonatal outcome, we have not found any significant difference in Apgar score of neonates at 5 mins, but there is significant difference in neonatal outcome at 1 min Apgar score between these two groups. Significantly, more number of the babies had 1 min Apgar score $<8$ in preloaded group compared to co-loaded group. Previous studies found no significant difference both in 1 and 5 mins Apgar, but those studies were conducted in elective CS without foetal distress where there was no urgency to deliver the baby.[11,16] In our set-up it was not possible to do umbilical blood gas analysis, so we relied totally on Apgar score.

\section{CONCLUSION}

Preloading can be safely avoided for spinal anaesthesia in CS posted for foetal distress. By using co-loading method, we can save valuable time required to deliver the baby and avoid circulatory overload without increasing incidence of hypotension.

\section{REFERENCES}

[1] Marx GF, Cosmi EV, Wollman SB. Biochemical status and clinical condition of mother and fetus at cesarean section. Anesth Analg 1969;48(6):986-93.

[2] Chestnut DH. Anesthesia and maternal mortality. Anesthesiology 1997;86(2):273-6.

[3] Abboud TK, Nagapppala S, Murakawa K, et al. Comparison of the effects of general and regional anesthesia for cesarean section on neonatal neurological and adaptive capacity scores. Anesth Analg 1985;64(10):996-1000.

[4] Downing JW, Howlton PC, Barclay A. Extradural analgesia for cesarean section: a comparison with general anesthesia. Br J Anaesth 1979;51(4):367-74.

[5] Corke BC, Datta S, Ostheimer GW, et al. Spinal anesthesia for cesarean section. The influence of hypotension on neonatal outcome. Anaesthesia 1982;37(6):658-62.

[6] Banerjee A, Stocche RM, Angle P, et al. Preload or coload for spinal anesthesia for elective Cesarean delivery: a meta-analysis. Can J Anesth 2010;57(1):2431.

[7] Mojica JL, Mele'ndez HJ, Bautista LE. The timing of intravenous crystalloid administration and incidence of cardiovascular side effects during spinal anesthesia: the results from a randomized controlled trial. Anesth Analg 2002;94(2):432-7.

[8] Dutta DC. Textbook of Obstretics: $6^{\text {th }}$ edn. Calcutta, India: New Central Book Agency Ltd., 2004: p. 221-2.

[9] Brull SJ, Greene NM. Zones of differential sensory block during extradural anaesthesia. $\mathrm{Br} \mathrm{J}$ Anaesth 1991;66(6):651-5.

[10] Buggy D, Higgins P, Moran C, et al. Prevention of spinal anesthesia-induced hypotension in the elderly: comparison between preanesthetic administration of crystalloids, colloids and no prehydration. Anesth Analg 1997;84(1):106-10.

[11] Jackson R, Reid JA, Thorburn J. Volume preloading is not essential to prevent spinal-induced hypotension at caesarean section. Br J Anaesth 1995;75(3):262-5.

[12] Hughes SC, Levinson G, Rosen MA. Anaesthesia for caesarean section. In: Hughes SC, Levinson G, Rosen MA. Shnider and Levinson's Anaesthesia for Obstetrics. $4^{\text {th }}$ edn. Philadelphia: Lippincott Williams \& Wilkins 2002: p. 206-7.

[13] Myles PS, Gin T. Statistical methods for anaesthesia and intensive care. $1^{\text {st }}$ edn. Oxford: Butterworth Heinemann 2000: p. 8-10.

[14] Carpenter RL, Caplan RA, Brown DL, et al. Incidence and risk factors for side effects of spinal anesthesia. Anesthesiology 1992;76(6):906-16.

[15] Tercanli S, Schneider M, Visca E, et al. Influence of volume preloading on uteroplacental and fetal circulation during spinal anaesthesia for caesarean section in uncomplicated singleton pregnancies. Fetal Diagn Ther 2002;17(3):142-6. 
[16] Rout CC, Akoojee SS, Rocke DA, et al. Rapid administration of crystalloid preload does not decrease the incidence of hypotension after spinal anaesthesia for elective caesarean section. $\mathrm{Br} \mathrm{J}$ Anaesth 1992;68(4):394-7.

[17] Marx GF, Luykx WM, Cohen S. Fetal-neonatal status following caesarean section for fetal distress. Br J Anaesth 1984;56(9):1009-13.

[18] MacLennan FM, MacDonald AF, Campbell DM. Lung water during the puerperium. Anaesthesia 1987;42(2):141-7.
[19] Carey JS, Scharschmidt BF, Culliford AT, et al. Hemodynamic effectiveness of colloid and electrolyte solutions for replacement of simulated operative blood loss. Surg Gynecol Obstet 1970;131(4):679-86.

[20] Sharma SK, Gajraj NM, Sidawi JE. Prevention of hypotension during spinal anesthesia: a comparison of intravascular administration of hetastarch versus lactated Ringer's solution. Anesth Analg 1997;84(1):111-4.

[21] Siddik-Sayyid SM, Nasr VG, Taha SK, et al. A randomized trial comparing colloid preload to coload during spinal anesthesia for elective cesarean delivery. Anesth Analg 2009;109(4):1219-24. 